\title{
Thermal performance of a vertical closed loop pulsating heat pipe and analysis using dimensionless numbers
}

\author{
G.V. Pradeep ${ }^{1}$ and K. Rama Narasimha ${ }^{2}$ \\ ${ }^{1}$ Jain University, Bangalore, Karnataka, 562112, India \\ Email: pradeep_gv99@yahoo.com \\ ${ }^{2}$ K.S. Institute of Technology, Bangalore, Karnataka, 560062, India
}

\begin{abstract}
This paper deals with the investigations on the thermal performance of a vertically oriented closed loop pulsating heat pipe (VCLPHP), both experimentally and by the use of dimensionless numbers. The working fluids used are acetone, ethanol, methanol and heptane. The VCLPHP consists of copper capillary tubes bent into five turns. The tube's inner and outer diameters are $2 \mathrm{~mm}$ and $3 \mathrm{~mm}$, respectively, and are made of copper. The lengths of the evaporator, adiabatic and condenser sections are $50 \mathrm{~mm}, 90 \mathrm{~mm}$ and $70 \mathrm{~mm}$, respectively. A constant fill ratio and a constant heat input of $60 \%$ and $80 \mathrm{~W}$, respectively, were used for the experimental investigations. The evaporator section was heated by means of a strip heater with a heating capacity of $400 \mathrm{~W}$. The condenser was cooled by circulating water. The experimental results showed that acetone is a better performer as compared to other fluids in terms of low thermal resistance and high heat transfer coefficient. Heptane showed the lowest thermal performance among all fluids. Ethanol and methanol showed average performance. The dimensional analysis was carried out using Kutateladze number, Prandtl number, Karman number, Bond number and Jacob number. Ethanol which showed an average performance in experimental investigations displayed the best thermal performance in terms of Prandtl number. With respect to Bond number, Karman number and Jacob number, acetone showed the best thermal performance. Heptane showed average thermal performance for all dimensionless numbers. Since the thermal performance of acetone both experimentally and by dimensional analysis was better than other working fluids, it may be considered as a suitable working fluid for application in PHP.
\end{abstract}

Key words: Vertical closed loop pulsating heat pipe; dimensionless numbers; working fluids; thermal performance

\section{INTRODUCTION}

Addressing thermal management issues of modern day electronic devices has emerged as a new challenge for scientists and engineers. Due to the ever increasing miniaturisation and compaction of electronic components, the heat generated from the devices is also increasing[1]. Conventional heat transfer devices, such as metal heat sinks, thermoelectric cooling, liquid jet impingement, etc. have been used in the past [2]. Their limitations in handling excess heat, high manufacturing cost, inability to be used in space and restricted applications have made them less popular[3]. Heat pipes are one method of removing excess heat but have certain limitations[4]. As a consequence, the oscillating heat pipes (OHPs) or pulsating heat pipes (PHPs) were first proposed by Akachi[5]. The advantages 
of simple design, easy fabrication and high heat transfer capabilities have made PHPs a suitable choice for dissipating high heat fluxes from electronic devices[6]. Over the recent years, PHPs have also found applications in other areas such as air preheating [7], radiators for space and terrestrial cooling[8], waste heat recovery [9], condenser for vapour compression refrigeration[10], cooling of fuel cell[11], heat exchangers[12], and evacuated tube solar collectors[13]. The PHP consists of a set of meandering tubes bent into many turns. It has different sections, such as evaporator, adiabatic and condenser (Figure 1) [14]. Although several designs of PHPs are available, the one found to be the most efficient is the closed loop pulsating heat pipe (CLPHP)[15]. The best orientation for operating the CLPHP is the vertical bottom heat mode (evaporator at the bottom and condenser at the top)[16]. Hence, this study mainly focused on vertically oriented closed loop PHP.

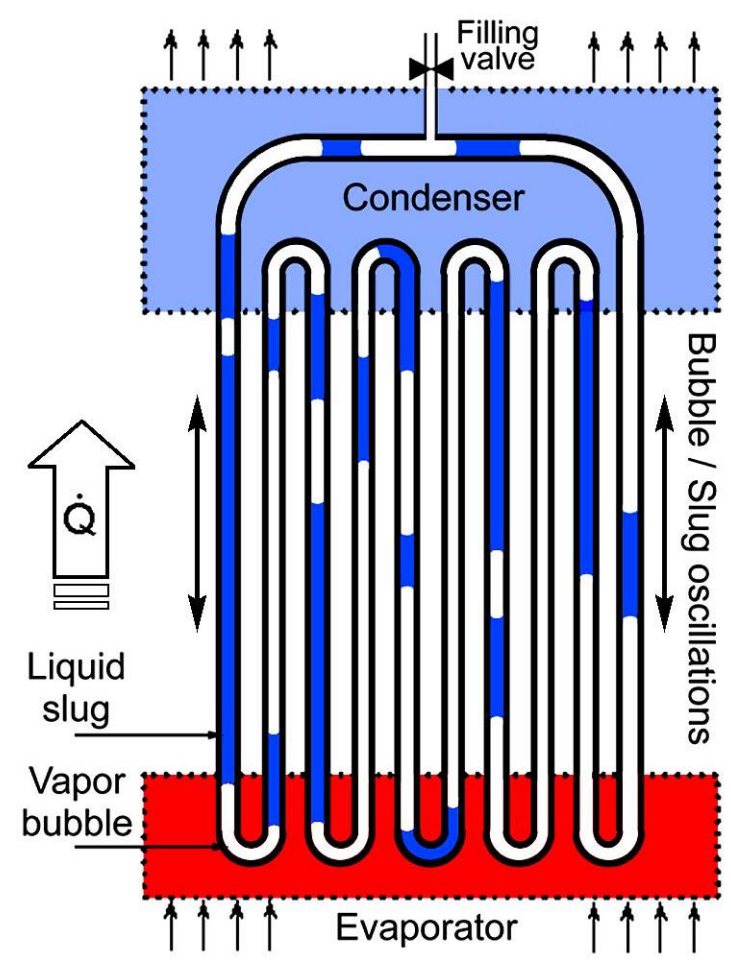

Figure 1. Schematic diagram of a closed loop pulsating heat pipe[14].

The PHP is fitted with small diameter tubes. The diameter chosen should be less than the critical diameter (equation1) [17, 18]. This facilitates the formation of liquid slugs and vapour bubbles inside the PHP. Hence, when the PHP is partially filled with a working fluid it distributes itself into liquid slugs and vapour bubbles [19]. The evaporator is heated by an external means and the condenser is cooled by circulating cold water or forced convection cooling by air. The working fluid vapourises by absorbing heat in the evaporator and loses heat in the condenser. The bubble formation in the evaporator by boiling and its sudden collapse in the condenser by condensation set up a pressure difference required for pumping the working fluid inside the VCLPHP. Hence, no external pumping is required to circulate the working fluid inside the PHP. The pumping of the fluid intermittently gives rise to pulsating flow and the hence the name given as pulsating heat pipes. The pulsating flow is sustained as long as the pressure difference exists between the evaporator and condenser[20]. From the research on PHP, it is widely 
accepted that the working fluid is mainly responsible for heat transfer in $\operatorname{PHP}[3,4,6,15]$. The quantity of heat transferred however, depends on the thermophysical properties of the working fluid used[18, 20-23]. The different thermophysical properties of interest are: surface tension $(\sigma)$, latent heat of vapourisation $\left(\mathrm{h}_{\mathrm{fg}}\right)$, saturation temperature $\left(\mathrm{T}_{\text {sat }}\right)$, density $(\rho)$, viscosity $(\mu)$, specific heat $(\mathrm{Cp})$ and change in pressure to change in temperature at saturated conditions (dP/dT) sat. Meena et al.[24] studied the thermal performance of a CLOHP with Check valves (CLOHP/CV). The inner diameter of the OHP was $1.7 \mathrm{~mm}$ having 10 turns. The working fluids used were R-123, ethanol and water. The fill ratio of $50 \%$ was maintained constant for all experiments. The authors observed that the critical heat flux decreased as the working fluids was changed from R123 to ethanol and water. With this, it was shown that critical heat flux varied inversely with latent heat of vapourisation of the working fluid. Piyanun Charoensawan et al.[25] conducted experimental investigations on two PHPs having tube inner diameters of $2 \mathrm{~mm}$ and $1 \mathrm{~mm}$. The working fluids used were again R-123, ethanol and water. The authors identified the contributions of sensible heat and latent heat in the heat transfer process of a PHP. They showed that the type of flow, flow velocity and pressure drop were influenced by the working fluid. Rama Narasimha et al.[26] studied the thermal performance of a single loop PHP using acetone, water, ethanol and methanol as the working fluids. They found the thermal performance of acetone was better as compared to other fluids, which recorded a low thermal resistance and a high heat transfer coefficient. The thermal performance was attributed to the low saturation temperature which resulted in faster boiling and the formation of vapour bubbles. A slightly higher value of latent heat of acetone stabilised the condenser wall temperature. Rudra Naik et al.[27] studied the thermal performance of a single loop PHP using acetone, ethanol and methanol as working fluids. They reported that, for ethanol, the fluctuations in wall temperature were higher as compared to other fluids due to its high latent heat, while acetone, having the lowest latent heat, showed minimum fluctuations. It was also pointed out that due to high specific heat values of methanol and ethanol over acetone, the heat carrying capacity of methanol and ethanol was higher than acetone. Zhang et al. [28] carried out experimental investigations on a three turn CLPHP using FC-72, ethanol and water. The authors observed that the amplitude of oscillations was small for FC-72 as compared to water and ethanol due to its low surface tension. However, FC-72 displayed faster movements as compared to other fluids due to its lower latent heat. It was concluded that FC-72 was more suitable for low heat flux applications. Halimi et al.[29] studied the thermal performance of CLPHPs made of Pyrex glass. Four different working fluids: acetone, ethanol, deionised water and copper nanofluid were investigated at different filling ratios of $40 \%, 50 \%$ and $60 \%$ with $40.5 \mathrm{~W}$ and $54 \mathrm{~W}$. Both horizontal and vertical orientations were used. For working fluids, it was summarised that with low latent heat, boiling temperature, surface tension, high specific heat and high (dP/dT) sat, a working fluid yields optimum performance.

From the above discussions, we note that the role of thermophysical properties is important in deciding the thermal performance of PHPs. Apart from the thermophysical properties, the thermodynamics involved in heat transfer and fluid circulation can also affect the thermal performance of PHPs[30]. In addition, physical parameters such as diameter, length, orientation, etc. can also have a bearing on the thermal performance based on the type of working fluid used[31, 32]. Combining both the thermal properties and physical properties can yield different results which are still not clear. One way to address this issue is by the use of dimensionless numbers which contain both the physical and fluid properties. Hence, this investigation involves the use of dimensionless numbers: 
Kutateladze number, Prandtl number, Karman number, Bond number and Jacob number [31-36].These dimensionless numbers are useful in comprehensively assessing the thermal performance of working fluids, both in terms of thermal and physical parameters. The results of the study can be useful for working fluid selection for the required application.

\section{METHODS AND MATERIALS}

\section{Experimental Setup}

A schematic diagram of the experimental setup is shown in (Figure 2). It consists of a five turn VCLPHP. The capillary tubes of VCLPHP are made of copper. The inner and outer diameters of the tubes are $2 \mathrm{~mm}$ and $3 \mathrm{~mm}$, respectively. The length of the evaporator, adiabatic and condenser sections are $50 \mathrm{~cm}, 90 \mathrm{~cm}$ and $75 \mathrm{~cm}$, respectively. The total length of the CLPHP is $204 \mathrm{~mm}$. The evaporator section was heated by means of two mica strip heaters, each of 200W capacity and well-insulated from all sides by packing glass wool. Heating was done by a regulated power supply using an auto transformer (Figure 2). The adiabatic section was provided with glass tubes made of borosilicate glass which also help in better flow visualisation. The silicone rubber tubes used here acted as connectors between copper tubes and glass tubes. The silicon rubber tubes are capable of withstanding temperatures up to $400^{\circ} \mathrm{C}$, are leak proof and can expand at high temperatures. The condenser section was provided with a cold water bath through which water circulates. Water was fed through a pipe connected to a water reservoir (tank). The exit water was passed into a water sink. The cold water flow rate was adjusted to $7 \mathrm{ml} / \mathrm{sec}$ to provide maximum cooling at the condenser. A total of eight K-type thermocouples (4 in the evaporator and 4 in the condenser section) were used to record temperatures at various points in the VCLPHP setup. The thermocouples were fixed on the surface of the copper tubes for recording temperature. The thermocouples were calibrated using hot and cold water and were found to be consistent with the calibration curve. The experiments were repeated in order to ensure the consistency of the thermocouples. The temperatures measured at different locations were recorded/logged into a desktop computer through the data logger (Figure 3). The temperature logging frequency was set to 1 data per sec.

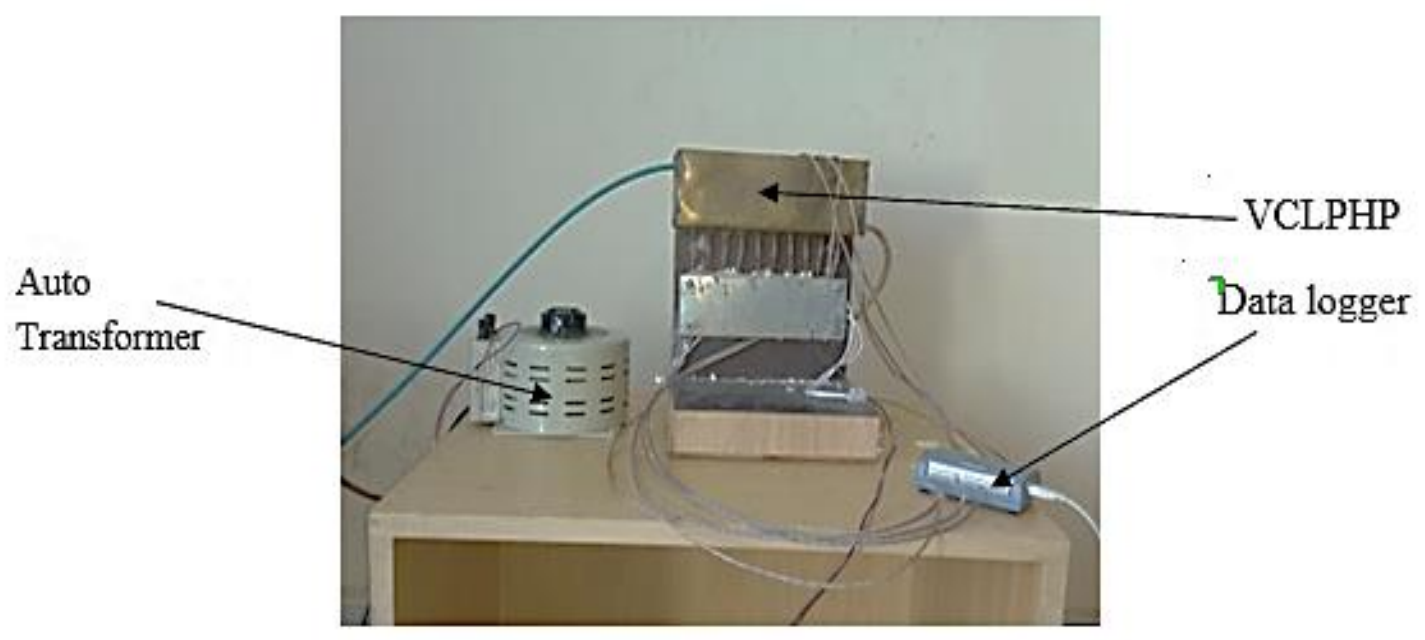

Figure.2 Experimental set up of VCLPHP. 


\section{Experimental Procedure}

Before starting the experiments, the PHP tubes were completely evacuated. A required quantity of the working fluid was then charged (in this case equal to a fill ratio of $60 \%$ ) into the tubes using a syringe. This fill ratio was thereafter maintained constant for all other experiments. The heating was started in the evaporator section by providing the required voltage and current using an auto transformer. After the evaporator was sufficiently heated (after 15 minutes), the data logger was switched ON to record the temperature readings from the thermocouples. Simultaneously, the cooling water flow was started through the condenser section. All the experiments were conducted in vertical bottom heating mode using the following working fluids: acetone, ethanol, methanol and heptane. The temperature data obtained was used for finding the parameters of thermal resistance and heat transfer coefficient.

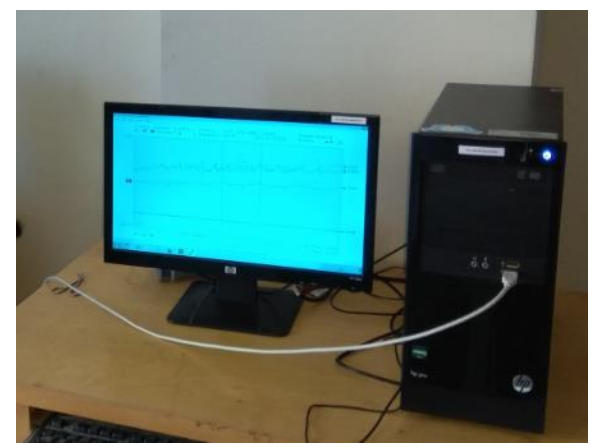

Figure.3 Computer for saving data

Table 1. Properties of working fluids at $80^{\circ} \mathrm{C}$ and $100^{\circ} \mathrm{C}$

\begin{tabular}{|c|c|c|c|c|c|c|c|}
\hline $\begin{array}{l}\text { Working } \\
\text { Fluid }\end{array}$ & $\begin{array}{c}\text { Evaporator } \\
\text { Temperature } \\
\left({ }^{\circ} \mathrm{C}\right)\end{array}$ & $\begin{array}{c}\text { Latent } \\
\text { heat } \\
(\mathrm{kJ} / \mathrm{kg})\end{array}$ & $\begin{array}{c}\text { Surface } \\
\text { tension }(\sigma) \\
\mathrm{N} / \mathrm{m}\end{array}$ & $\begin{array}{l}\text { Dynamic } \\
\text { Viscosity } \\
\left(\mathrm{N}-\mathrm{s} / \mathrm{m}^{2}\right)\end{array}$ & $\begin{array}{l}\text { Saturation } \\
\text { temperature } \\
\left({ }^{\circ} \mathrm{C}\right)\end{array}$ & $\begin{array}{c}\text { Specific heat } \\
\left(\mathrm{C}_{\mathrm{pl}}\right) \\
(\mathrm{kJ} / \mathrm{kg}-\mathrm{K})\end{array}$ & $\begin{array}{l}\text { Density } \\
\left(\mathrm{kg} / \mathrm{m}^{3)}\right.\end{array}$ \\
\hline \multirow[b]{2}{*}{ Acetone } & 80 & 495 & $16.2 \times 10^{-3}$ & $0.192 \times 10^{-3}$ & \multirow[b]{2}{*}{56.25} & 2.39 & 719 \\
\hline & 100 & 472 & $13.4 \times 10^{-3}$ & $0.17 \times 10^{-3}$ & & 2.49 & 690 \\
\hline \multirow[b]{2}{*}{ Ethanol } & 80 & 960 & $17.3 \times 10^{-3}$ & $0.432 \times 10^{-3}$ & \multirow[b]{2}{*}{78.3} & 3.03 & 757 \\
\hline & 100 & 927 & $15.5 \times 10^{-3}$ & $0.318 \times 10^{-3}$ & & 3.30 & 730 \\
\hline \multirow[b]{2}{*}{ Methanol } & 80 & 1084 & $17.5 \times 10^{-3}$ & $0.271 \times 10^{-3}$ & \multirow[b]{2}{*}{64.7} & 2.52 & 735 \\
\hline & 100 & 1030 & $15.7 \times 10^{-3}$ & $0.214 \times 10^{-3}$ & & 2.52 & 714 \\
\hline \multirow{2}{*}{ Heptane } & 80 & 330.1 & $14.35 \times 10^{-3}$ & $0.239 \times 10^{-3}$ & \multirow{2}{*}{98.43} & 2.47 & 631 \\
\hline & 100 & 316.7 & $12.47 \times 10^{-3}$ & $0.198 \times 10^{-3}$ & & 2.57 & 612 \\
\hline
\end{tabular}

Critical Diameter

The equation for critical diameter is given by:

$$
D_{\text {critical }}=2 \sqrt{\frac{\sigma}{g\left(\rho_{l}-\rho_{v}\right)}}
$$


where, $D$ critical $=$ critical diameter in $\mathrm{m} ; \sigma=$ surface tension, $\mathrm{N} / \mathrm{m} ; g=$ acceleration due to gravity, $\mathrm{m} / \mathrm{s}^{2} ; \rho_{l}=$ liquid density, $\mathrm{kg} / \mathrm{m}^{3} ; \rho_{v}=$ vapour density, $\mathrm{kg} / \mathrm{m}^{3}$

\section{Thermal Resistance}

The thermal resistance of a PHP is given by:

$$
R_{t h}=\frac{T_{e}-T_{c}}{Q}
$$

where, $\mathrm{R}_{\mathrm{th}}=$ Thermal resistance, $\mathrm{K} / \mathrm{W} ; \mathrm{T}_{\mathrm{e}}=$ Evaporator temperature, $\mathrm{K} ; \mathrm{T}_{\mathrm{c}}=$ Condenser temperature, $\mathrm{K} ; \mathrm{Q}=$ Heat input, $\mathrm{W}$.

\section{Heat Transfer Coefficient}

The heat transfer coefficient of a PHP is given by

$$
h=\frac{Q}{A_{s}\left(T_{e}-T_{c}\right)}
$$

where, $\mathrm{h}=$ convective heat transfer coefficient, $\mathrm{W} / \mathrm{m}^{2} \mathrm{~K} ; \mathrm{T}_{\mathrm{e}}=$ Evaporator temperature, $\mathrm{K} ; \mathrm{T}_{\mathrm{c}}=$ Condenser temperature, $\mathrm{K} ; \mathrm{Q}=$ Heat input, $\mathrm{W} ; \mathrm{A}_{\mathrm{s}}=$ surface area, $\mathrm{m}^{2}$.

\section{Non-dimensional numbers}

The thermal performance analysis of the PHP was carried out using different dimensionless numbers. The dimensionless used are Kutateladze number $(\mathrm{Ku})$, Prandtl number (Pr), Bond number (Bo) and Karman number (Ka). In this analysis, Ku was taken to be the standard for comparison as it represents the thermal performance.

\section{Kutateledze number}

Kutateledze number is a dimensionless number representing thermal performance. It is a ratio of output heat flux to the theoretical heat flux as given by Equation 4. The higher the $\mathrm{Ku}$, the higher the heat transferred from the heat pipe and vice-versa [30]. The output heat flux was obtained from Equation 4 and the input heat flux was obtained from Equation 5 by considering the thermal properties of the working fluid. The thermal performance of the working fluid was compared by plotting the values of $\mathrm{Ku}$ on $\mathrm{X}$-axis and the values of other dimensionless numbers on y-axis.

$$
K u=\frac{\dot{q}_{c}}{\left(\sigma g\left[\frac{\rho_{l}-\rho_{v}}{\rho_{v}^{2}}\right]\right)^{1 / 4} h_{f g} \rho_{v}}
$$

where, $\sigma=$ surface tension of the liquid, $\mathrm{N} / \mathrm{m} ; \mathrm{g}=$ acceleration due to gravity, $\mathrm{m} / \mathrm{s}^{2} ; \rho_{1}=$ liquid density, $\mathrm{kg} / \mathrm{m}^{3} ; \rho_{\mathrm{v}}=$ vapour density, $\mathrm{kg} / \mathrm{m}^{3} ; \mathrm{h}_{\mathrm{fg}}=$ latent heat of vapourisation, $\mathrm{kJ} / \mathrm{kg}$; $\dot{q}_{c}=$ heat flux dissipated at the condenser end, $\mathrm{W} / \mathrm{m}^{2}$ can be obtained by the following relation.

$$
\dot{q}_{c}=\frac{\dot{m}_{c} C_{p c}\left(T_{o}-T_{i}\right)}{A_{c}}
$$


where, $\dot{m}=$ mass flow rate of coolant (water) in the condenser, $\mathrm{kg} / \mathrm{s} ; C_{p c}=$ specific heat of coolant (water), $\left(4.18 \mathrm{~kJ} / \mathrm{kg}^{\circ} \mathrm{C}\right) ; T_{o}=$ temperature of coolant at the outlet of the condenser, ${ }^{\circ} \mathrm{C} ; T_{i}=$ temperature of coolant at the inlet of the condenser, ${ }^{\circ} \mathrm{C}$

\section{Prandtl Number}

Prandtl number is a dimensionless number which relates different working fluid properties. It is the ratio of the dynamic viscosity of the fluid to its thermal diffusion (equation 6). In this analysis, only Prandtl number applicable for liquid $\left(\operatorname{Pr}_{l}\right)$ was considered and Prandtl number for vapour $\left(\mathrm{Pr}_{v}\right)$ was neglected since its contribution was negligible.

$$
P_{r l}=\frac{\mu_{l} C_{p l}}{k_{l}}
$$

where, $P_{r l}=$ Prandtl number for liquid; $\mu_{l}=$ dynamic viscosity, $\mathrm{N}-\mathrm{s} / \mathrm{m}^{2} ; C_{p l}=$ specific heat of liquid, $\mathrm{kJ} / \mathrm{kg}-\mathrm{K} ; \mathrm{k}_{\mathrm{l}}=$ thermal conductivity of liquid, $\mathrm{W} / \mathrm{mK}$

\section{Bond Number}

Bond number is a dimensionless number relating the properties of working fluid with flow geometry (diameter). It is defined as the ratio of buoyancy force to surface tension forces. It is given by the following equation:

$$
B_{o}=\frac{g\left(\rho_{l}-\rho_{v}\right) D_{i}^{2}}{\sigma}
$$

where, $B_{o}=$ Bond number; $g=$ acceleration due to gravity, $\mathrm{m} / \mathrm{sec}^{2} ; \rho_{l}=$ liquid density, $\mathrm{kg} / \mathrm{m}^{3} ; \rho_{v}=$ vapour density, $\mathrm{kg} / \mathrm{m}^{3} ; D_{i}=$ inner diameter of the tube, $\mathrm{m} ; \sigma=$ Surface tension, $\mathrm{N} / \mathrm{m}$.

\section{Karman Number}

Karman number is a dimensionless number relating the working fluid's properties with the geometry of the PHP. It is the ratio of the driving force to the frictional force of the working fluid. It is given by Equation 8 .

$$
\mathrm{Ka}=\frac{\rho_{l}\left(\Delta_{p}\right)_{s a t}^{e-c} D_{i}^{3}}{\mu_{l}^{2} L_{e f f}}
$$

where, $\rho_{l}=$ density of liquid in $\mathrm{kg} / \mathrm{m}^{3} ;\left(\Delta_{p}\right)_{s a t}^{e-c}=$ pressure difference between evaporator and condenser at saturated temperature in ${ }^{\circ} \mathrm{C}$; $\mathrm{Di}=$ inner diameter in $\mathrm{m} ; \mu_{l}=$ dynamic viscosity in $\mathrm{N}-\mathrm{s} / \mathrm{m}^{2}$ and $\mathrm{L}_{\mathrm{eff}}=$ effective length in $\mathrm{m} ; \mathrm{L}_{\mathrm{e}}=$ evaporator length; $\mathrm{L}_{\mathrm{a}}=$ adiabatic section length and $\mathrm{L}_{\mathrm{c}}=$ condenser length.

\section{Jacob Number}

Jacob number is a dimensionless number involved with the working fluid properties (Equation 9). It is the ratio of heat transferred by the PHP through latent heat and sensible 
heat. Latent heat causes phase change from liquid to vapour and sensible heat raises the temperature of the working fluid.

$$
\mathrm{Ja}=\frac{h_{f g}}{C_{p l}(\Delta T)_{s a t}^{e-c}}
$$

where, $\mathrm{Ja}=\mathrm{Jacob}$ number; $\mathrm{h}_{\mathrm{fg}}=$ latent heat of vapourisation, $\mathrm{kJ} / \mathrm{kg} ; \quad(\Delta T)_{\text {sat }}^{e-c}=$ Temperature difference between evaporator and condenser at saturated conditions in ${ }^{\circ} \mathrm{C}$; $C_{p l}=$ specific heat of liquid, $\mathrm{kJ} / \mathrm{kg}-\mathrm{K}$

\section{RESULTS AND DISCUSSION}

\section{Effect of working fluids on the evaporator temperature}

Figure 4 shows the variations of evaporator temperature versus time for the different working fluids for a heat input of $80 \mathrm{~W}$ and fill ratio of $60 \%$. It can be observed that with the passage of time, the evaporator temperature $T_{e}$, gradually increases for all the fluids. At a steady state, the evaporator wall temperature is high in case of heptane and is the least in the case of acetone. Referring to the thermophysical properties from Table 1, we note that saturation temperature of heptane is the highest at $98.3^{\circ} \mathrm{C}$ while for acetone, it is the lowest at $56.2^{\circ} \mathrm{C}$. To reach the saturation temperature, heptane takes a longer time while acetone takes less time. In this time duration, there is an appreciable rise in evaporator temperature for heptane and for acetone, it is comparatively lower. Furthermore, from the same table, we also note that the latent heat of acetone is higher than that of heptane. Although a low latent heat aids in faster bubble formation[37], due to the high saturation temperature of heptane, the bubble formation time is more while it is less for acetone. Hence, the bubbles are formed more quickly in acetone than in the case of heptane. Since the bubble formation pulsating action started quickly, the heat transfer took place quickly to the condenser which also lowered the evaporator temperature for acetone.

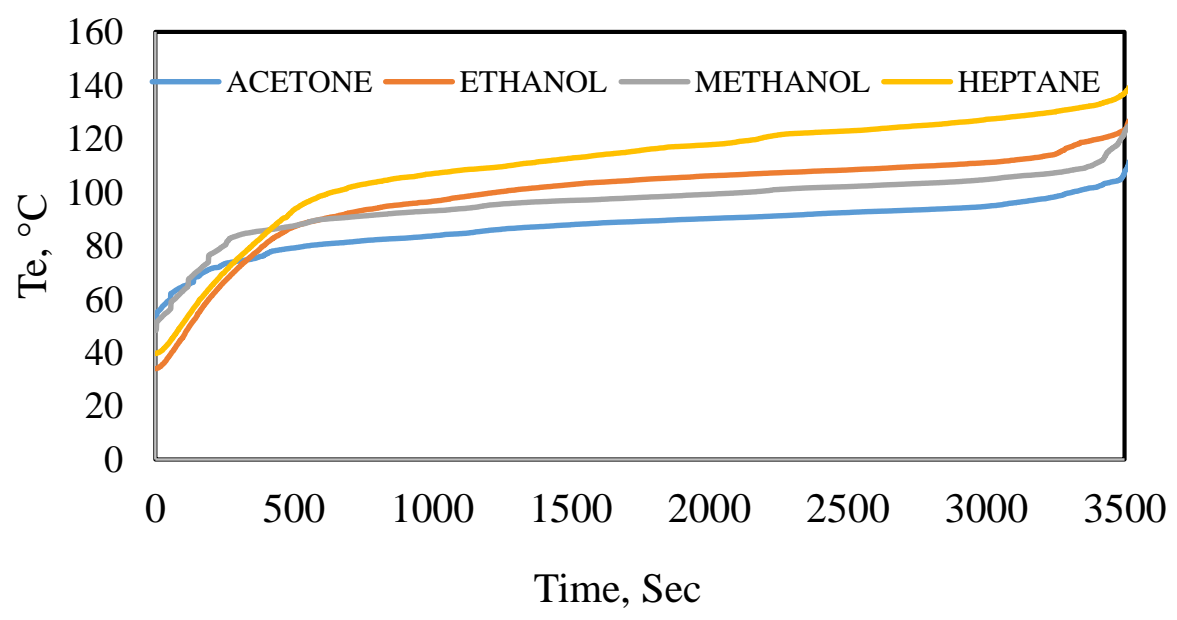

Figure 4. Variation of evaporator temperature for different fluids.

\section{Effect of Working Fluid on Temperature Difference $\left(T_{e}-T_{c}\right)$ With Time}

Figure 5 shows the variation of temperature difference between evaporator and condenser $\left(T_{e}-T_{c}\right)[26,27]$ for different working fluids at a constant heat input of $80 \mathrm{~W}$ and for a fill ratio of $60 \%$. From Figure 5 , it can be observed that $\left(T_{e}-T_{c}\right)$ values for heptane are 
comparatively higher than other fluids. Higher values of $\left(T_{e}-T_{c}\right)$ suggest the heat accumulation in the evaporator and less heat dissipation in the condenser[26]. As a consequence, heat transported to the condenser end is less. In the case of heptane, having a low latent heat and higher saturation temperature (Table 1) delays the formation of vapours and hence the circulation of heptane inside the PHP is also delayed. During the time delay, the temperature builds up in the evaporator and since no heat is dissipated to the condenser, the temperature difference $\left(T_{e}-T_{c}\right)$ increases in the case of heptane. In the case of acetone, due to low saturation temperature and slightly higher value of latent heat than heptane, acetone evaporates quickly and hence circulation is quickly established[37, 38]. The circulation of acetone helps in dissipation of heat to the condenser. This results in lowering the temperature difference $\left(T_{e}-T_{c}\right)$ with time for acetone, as seen in Figure 5.

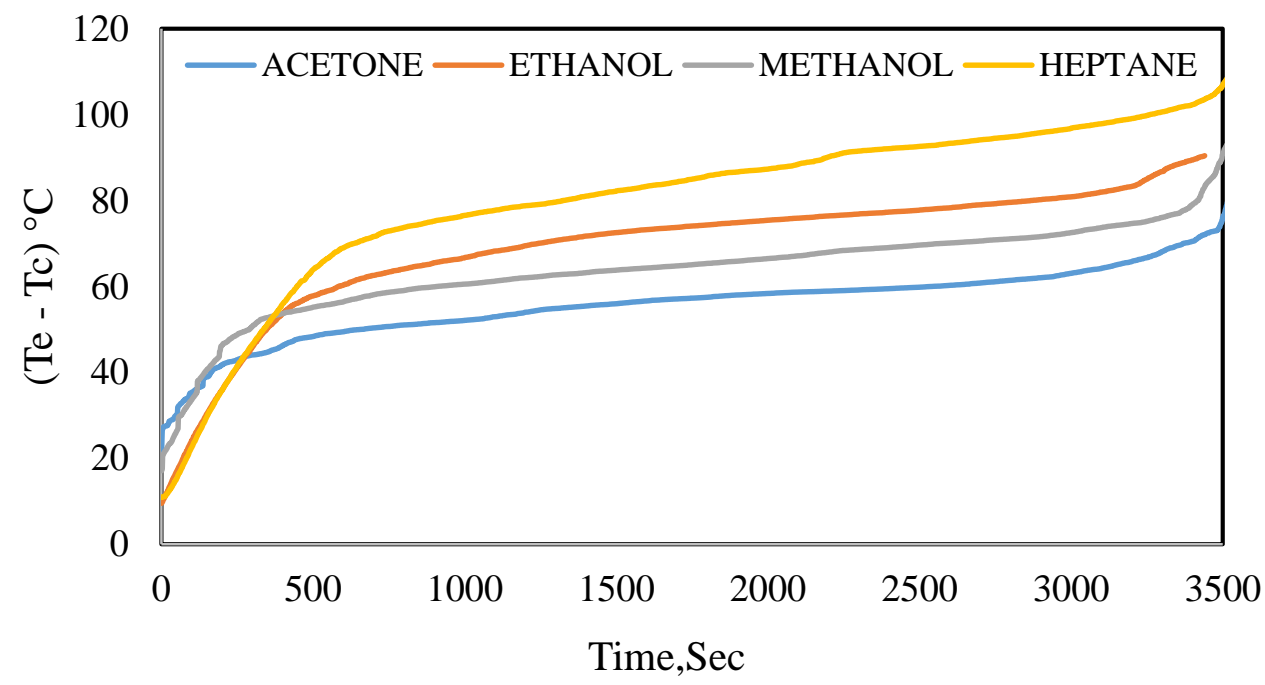

Figure 5. Variation of $\left(T_{e}-T_{c}\right)$ for different working fluids.

\section{Effect of Working Fluid on Thermal Resistance}

Figure 6 shows the variation of thermal resistance for different working fluids at heat input of 80 watts and fill ratio of $60 \%$ at steady state conditions. Among all fluids used, acetone has the lowest thermal resistance and heptane the highest. This attributed to the temperature difference between evaporator and condenser, being the lowest for acetone and highest for heptane. From equation 2, we note that the thermal resistance $\mathrm{R}_{\text {th }}$ is directly proportional to the temperature difference $\left(T_{e}-T_{c}\right)$. Hence, as $\left(T_{e}-\right.$ $T_{c}$ ) reduces, the value of thermal resistance also decreases. From Table 1, it is noted that acetone has a slightly higher latent of vapourisation and the lowest saturation temperature as compared to other fluids[26]. The viscosity of acetone is also the least among all fluids. Hence, the bubble formation is faster as compared to other fluids. This is also supported by the low viscosity of acetone which helps it to circulate faster inside the PHP. Meanwhile, although heptane has the lowest latent heat, its saturation temperature is high [27]. The viscosity is a bit higher. Hence, bubble formation is slower and with low circulation rate, the temperature difference will be higher. For ethanol and methanol, the latent heat is higher as compared to acetone and heptane which delays the bubble formation[38]. Hence, $\left(T_{e}-T_{c}\right)$ is higher for ethanol and methanol, resulting in higher thermal resistance. 


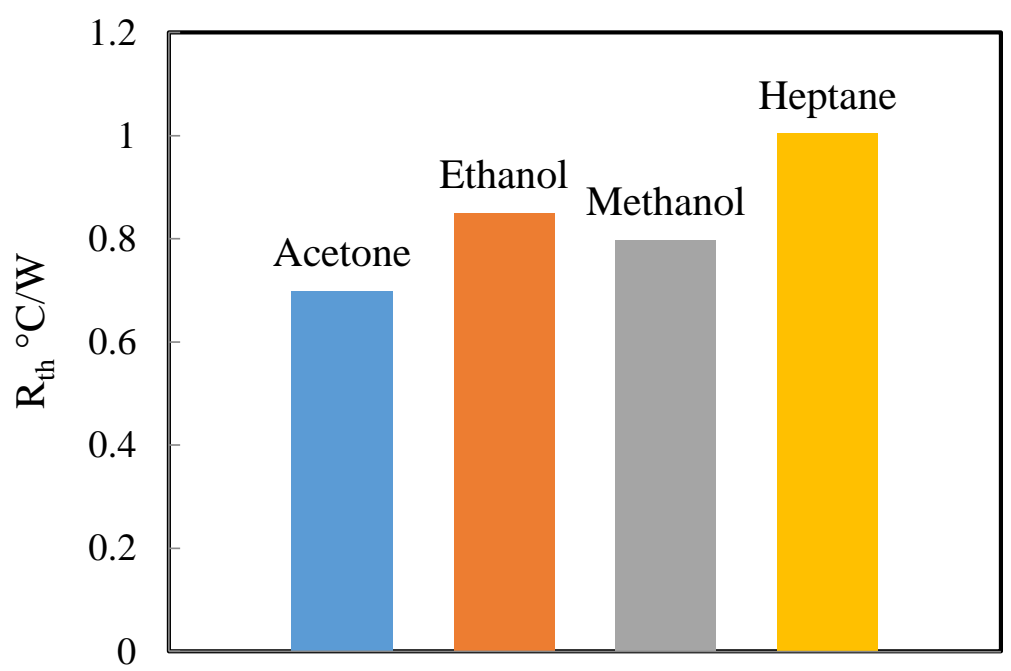

Figure 6. Variation of Thermal resistance $\left(\mathrm{R}_{\mathrm{th}}\right)$ for different working fluids.

\section{Effect of Working Fluid on Heat Transfer Coefficient}

Figure 7 shows the variation of the heat transfer coefficient for different working fluids at steady state for a heat load of 80 watts and fill ratio of $60 \%$. It is observed that heat transfer coefficient is the highest for acetone and lowest for heptane. Again, from the equation of heat transfer coefficient equation (equation 3), we note that the heat transfer coefficient is inversely proportional to the temperature difference $\left(T_{e}-T_{c}\right)$. With the increase in temperature difference, the heat transfer coefficient $h$ reduces. Hence, a working fluid with highest thermal resistance will provide the lowest heat transfer coefficient. By the acetone's low surface tension and density combined with low latent heat and saturation temperature, a better flow is possible in the case of acetone as compared to other fluids. This results in a better heat transfer ability in the condenser and consequently, the heat transfer coefficient also improves as seen in Figure 7. For other fluids, since the circulation is not as good as acetone, lower heat dissipation occurs in the condenser [26, 27]. Hence, heat transfer coefficient is reduced as shown in Figure 7 . The experimental investigations have yielded important results which can be used for further investigations in analytical studies using non-dimensional numbers.

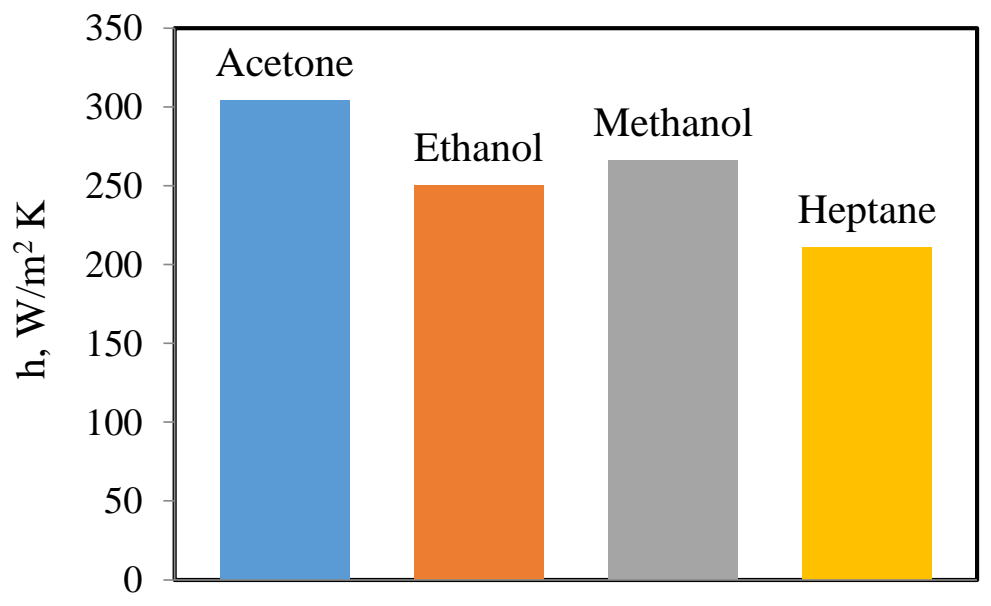

Figure 7. Variation of heat transfer coefficient (h) for different working fluids. 


\section{Variation of Thermal Performance based on Prandtl Number}

Figure 8 shows the variation of thermal performance for different working fluids based on Prandtl number. With the increase in Pr, the thermal performance increases as seen from Figure 8, showing an increasing trend. Although acetone showed the best performance experimentally, it underperformed as compared to other fluids. Whereas ethanol, which showed an average performance experimentally, is seen to perform better than all the working fluids. This may be due to the capacity of the working fluid to carry more heat owing to its high specific heat and high viscosity (Equation 6)[31]. With high specific heat, the heat carrying capacity of the fluid increases and with high viscosity, the fluid circulates slowly inside the PHP and consequently has more time to absorb heat. If the working fluid has high thermal conductivity, it tends to dissipate the heat absorbed, but a working fluid with low thermal conductivity conducts less heat[32]. Hence, with the increase in Pr, the thermal performance increases.

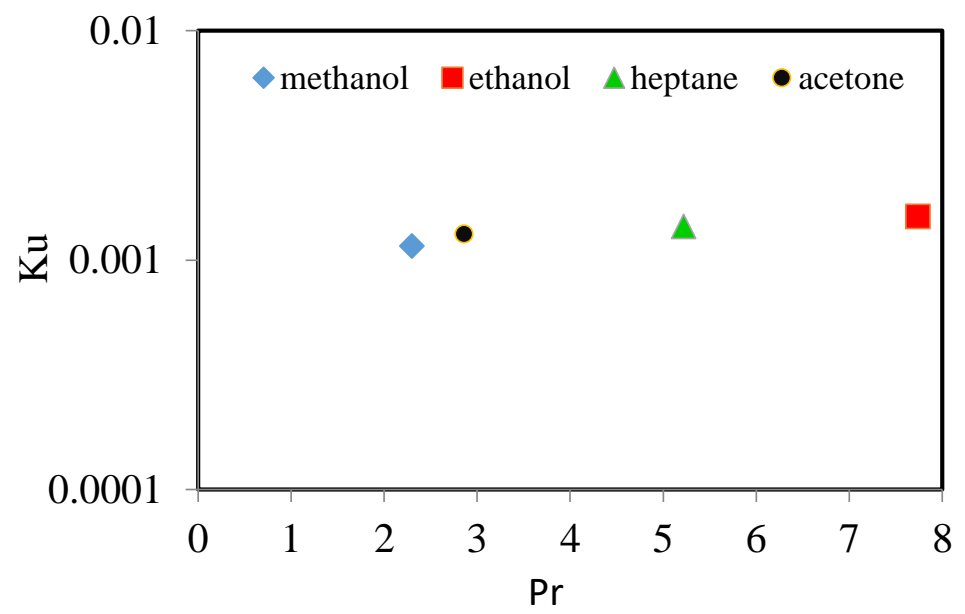

Figure 8. Variation of thermal performance $(\mathrm{Ku})$ for different fluids based on $\mathrm{P}_{\mathrm{r}}$.

\section{Variation of Thermal Performance based on Bond number}

It can be observed from Figure 9 that, acetone with a bond number of 1.73 provides a better thermal performance $(\mathrm{Ku})$ as compared to other fluids like methanol, ethanol and heptane. From Equation 8, it may be observed that as the surface tension decreases, Bond number increases. This is because, the vapour bubbles formed will not be longer but instead split into smaller bubbles[31]. The bubbles being smaller carry lesser mass and hence, heat carried by them is also less. When Bo increases, the heat transfer and the thermal performance reduce. In the numerator of Equation 8, when the difference in densities between liquid and vapour increases, the vapour density decreases and hence the bubbles become lighter. The lighter bubbles move easily from the evaporator towards the condenser and improves heat transfer. Therefore, as Bo increases, heat transfer also increases. Since the inner diameter is constant, its effect may not be observed in this case. Heptane, having the lowest surface tension, also has a low liquid density. Thus, although Heptane has the highest bond number of 2.16, it has a low thermal performance $(\mathrm{Ku})$. Ethanol and methanol with slightly higher values of surface tension and density show lower thermal performances[37]. From Figure 9, it may be noted that no particular trend is evident in the variation of Bo against $\mathrm{Ku}$. Rather, the Bond number initially tends to decrease but later increases. Acetone displays the best thermal performance while heptane the lowest thermal performance. 


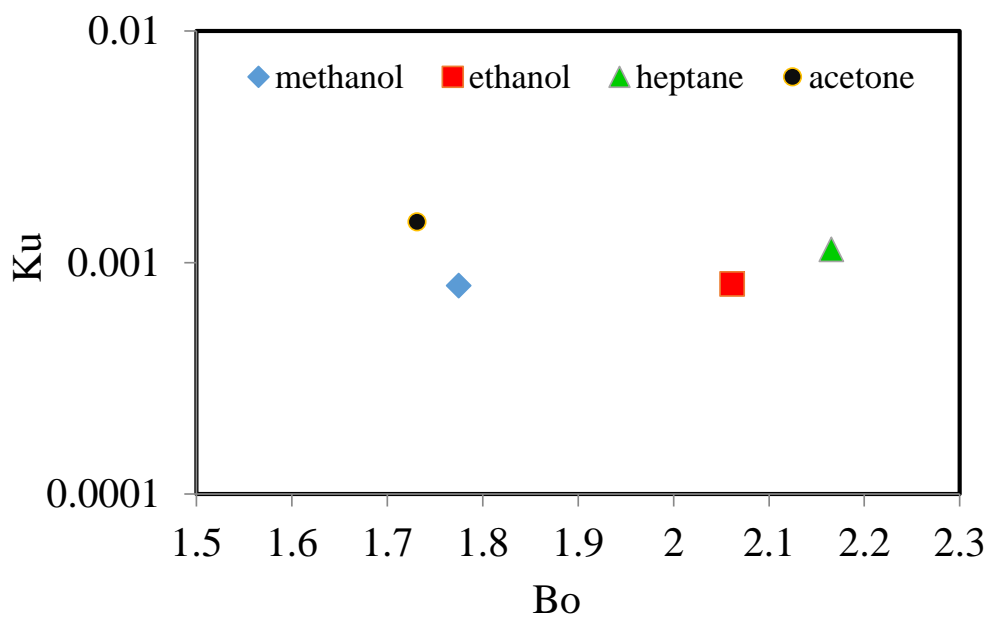

Figure 9. Variation of thermal performance $(\mathrm{Ku})$ for different fluids based on Bo.

\section{Variation of Thermal Performance based on Karman number}

Similar to the Bond number, the Karman number relates working fluid properties with the geometry of the PHP (Equation 9). The pressure difference between evaporator and condenser $(\Delta \mathrm{p})$ sat is the actual driving force in a PHP. By using tubes of a single diameter and for a particular working fluid with a certain density, an increase in the pressure difference improves the circulation of the working fluid. With a better movement of the fluid, the heat transfer also improves. In this case, the effective length $\left(\mathrm{L}_{\mathrm{eff}}=\right.$ $\left.0.5 \mathrm{~L}_{\mathrm{e}}+\mathrm{L}_{\mathrm{a}}+0.5 \mathrm{~L}_{\mathrm{c}}\right)$ was made constant and viscosity $\left(\mu_{l}\right)$ was varied by changing the working fluids[31]. Hence, as the fluid viscosity $\left(\mu_{l}\right)$ increases, Ka decreases (Figure 10). Acetone, with the least viscosity and high pressure difference between evaporator and condenser, shows best thermal performance[38]. Ethanol, having the highest viscosity, shows a low thermal performance[39].

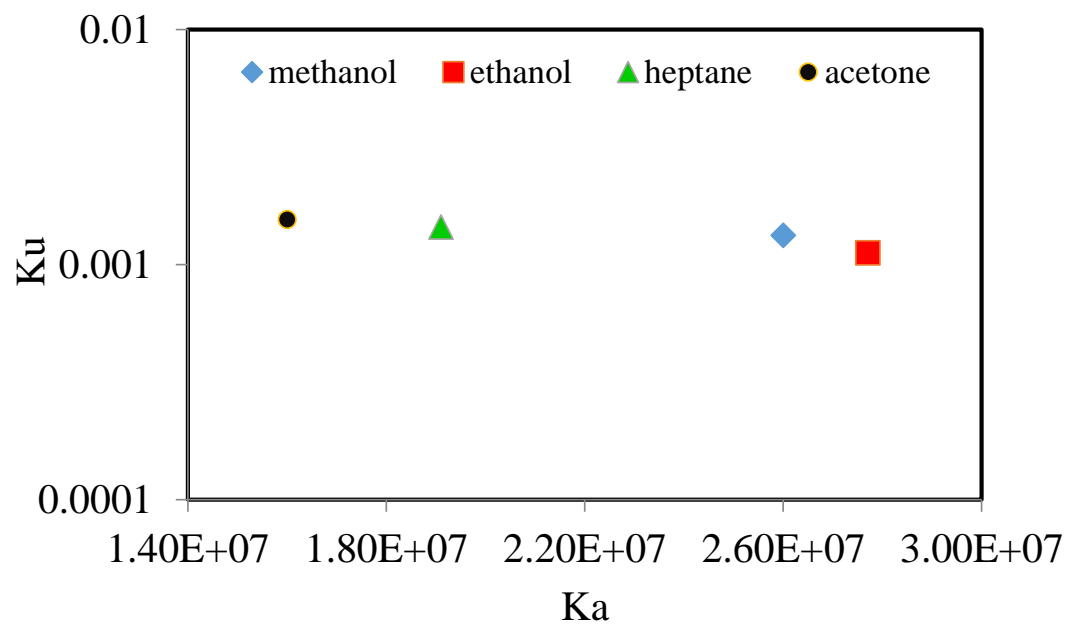

Figure 10. Variation of thermal performance $(\mathrm{Ku})$ for different fluids based on Ka.

\section{Variation of Thermal Performance based on Jacob Number}

The numerator of equation 10 contains the term $h_{f g}$ for heat transfer through phase change and the denominator has $C_{p l}$ for heat transfer through sensible heat. From Figure 11, we 
note that there is no particular trend followed by the working fluids in showing the thermal performance. However, acetone with a Jacob number of 5.73 shows the best thermal performance and heptane with the lowest Ja number of 1.42 shows average thermal performance. Ethanol and methanol display the lowest thermal performance with Ja numbers of 3.06 and 6.81, respectively. Although acetone has a lower latent heat of vapourisation (Table 1), its specific heat is the lowest. Also, from experimental investigations, we note that the temperature difference between evaporator and condenser is the lowest for acetone. Hence, acetone has a higher Ja value combined with the best thermal performance. Methanol, although having the highest latent heat, has the highest Ja number (6.81) but its thermal performance is lower than acetone due to large temperature difference between evaporator and condenser (equation 10)[31, 40]. For the same reason, ethanol also has a lower thermal performance. Heptane, having the lowest latent heat value, has the lowest Ja number due to high specific heat combined with the highest temperature difference between evaporator and condenser (Equation 10) [32].

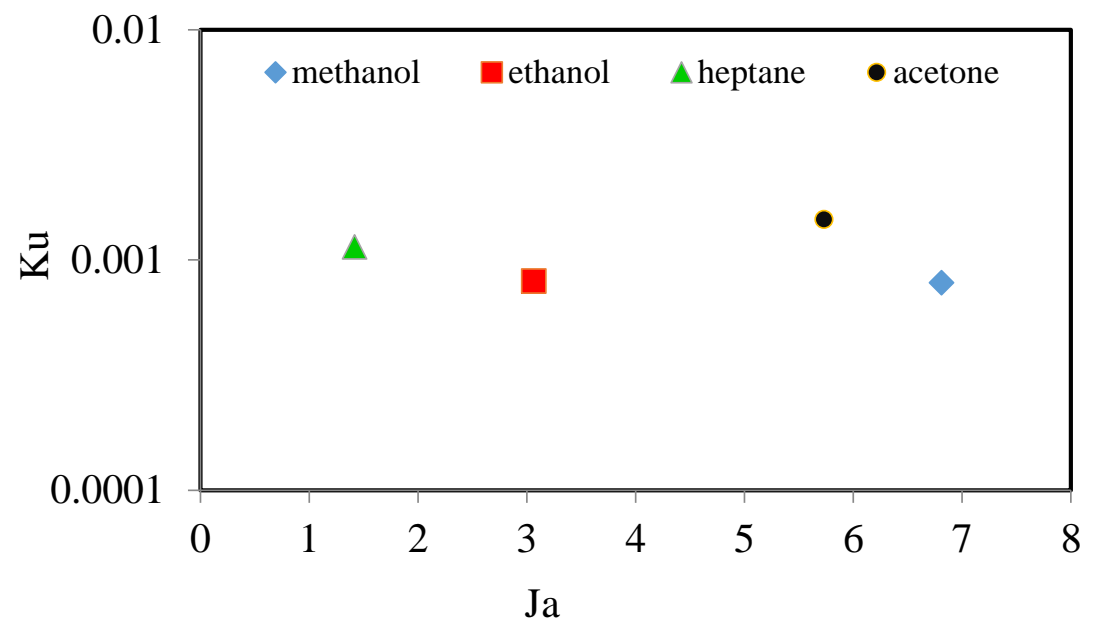

Figure 11. Variation of thermal performance $(\mathrm{Ku})$ for different fluids based on Ja.

\section{CONCLUSIONS}

The experimental investigations and analysis using dimensional numbers to determine the effect of thermal performance on a VCLPHP have been carried out and the following conclusions are drawn.

1) The temperature difference between evaporator and condenser was the highest for heptane and lowest for acetone; consequently, the thermal resistance was the lowest and heat transfer coefficient was the highest for acetone.

2) Thermal performance displayed by acetone was the best among all other fluids.

3) The thermal performance of all fluids displayed an increasing trend with respect to Prandtl number. Ethanol having the highest Prandtl number records the best performance, while methanol having the lowest Prandtl displayed the lowest performance.

4) No particular trend of variation is observed for all working fluids in the case of Bond number. However, acetone has the lowest bond number it provides the highest thermal performance. 
5) As the Karman number increases, the thermal performance of the working fluids decrease. As the Karman number for acetone is the lowest, it showed the highest performance.

6) No particular trend in the thermal performance for all working fluids is observed in the case for Jacob number. Although acetone had a slightly lower Ja number than methanol, it provides the best performance in terms of Jacob number.

The thermal performance of ethanol was found to be better in terms of Prandtl number, but with respect to other dimensionless numbers, acetone showed better thermal performance. It may be concluded both experimentally and by dimensional analysis that acetone outperformed other working fluids. Hence, acetone may be considered as a suitable working fluid for application in PHPs. This study has also brought to light the importance of thermophysical properties and their effect when combined with other properties, thereby giving a realistic picture of the performance of the working fluids and their selection. Furthermore, the study can be extended for deriving a correlation by considering all the dimensionless numbers used in the present study. The correlation derived can be useful in optimising the design of PHPs.

\section{ACKNOWLEDGEMENTS}

The authors would like to thank Jain University for providing the necessary research facilities which helped in the smooth conduction of the research work. There was no external funding applicable for the present research.

\section{REFERENCES}

[1] Anandan SS, Ramalingam V. Thermal management of electronics: A review of literature. Thermal Science. 2008;12:5-26.

[2] Frijns AJ, Eummelen EH, Nedea SV, Nicole CC, Van Steenhoven AA. Microchannel cooling: simulations and experiments. Turbulence: International Journal. 2004;10:67-74.

[3] Mohammadi N, Mohammadi M, Shafii MB. A review of nanofluidic pulsating heat pipes: suitable choices for thermal management of electronics. Frontiers in Heat Pipes. 2013;3:1-17.

[4] Faghri A. Heat pipes: review, opportunities and challenges. Frontiers in Heat Pipes. 2014;5:1-48.

[5] Akachi H. Structure of a heat pipe. USA, Patent 4921041. 1990.

[6] Karimi G, Culham J. Review and assessment of pulsating heat pipe mechanism for high heat flux electronic cooling. IEEE Ninth Intersociety Conference on Thermal and Thermomechanical Phenomena in Electronic Systems. 2004;52-9.

[7] Meena P, Rittidech S, Poomsa-Ad N. Application of closed-loop oscillating heatpipe with check valves (CLOHP/CV) air-preheater for reduced relative-humidity in drying systems. Applied Energy. 2007;84:553-64.

[8] Khandekar S, Gupta A. Embedded pulsating heat pipe radiators. Proceedings of the 14th International Heat Pipe Conference, Florianopolis, Brazil.2007;22-7.

[9] Meena P, Rittidech S. Waste Heat Recovery by Closed-Loop Oscillating Heat Pipe with Check Valve from Pottery Kilns for Energy Thrift. American Journal of Engineering and Applied Sciences. 2008;1:126-30.

[10] Yeunyongkul P, Sakulchangsatjatai P, Kammuang-lue N, Terdtoon P. Experimental investigation of the closed loop oscillating heat pipe condenser for 
vapor compression refrigeration. Journal of Applied Science and Engineering. 2012;15(2):117-22.

[11] Clement J, Wang X. Design and testing of an oscillating heat pipe for fuel cell cooling applications. Proceedings of the ASME International Mechanical Engineering Congress \& Exposition, Denver, Colorado, USA, 2011.

[12] Patel CD, Selokar G, Paul A. Pulsating Heat Pipe Based Heat Exchanger. International Journal of Engineering Research and Science \& Technology. 2012;1:12-8.

[13] Ha SJ, Kim JS, Lee SI, Jeong BH. The study of evacuated solar collector using pulsating heat pipe. Frontiers in Heat Pipes. 2012;3:1-5.

[14] Khandekar S, Groll M, Luckchoura V. An introduction to pulsating heat pipes. Electronics Cooling. 2003;9:38-42.

[15] Zhang Y, Faghri A. Advances and unsolved issues in pulsating heat pipes. Heat Transfer Engineering. 2008;29:20-44.

[16] Yang H, Khandekar S, Groll M. Operational limit of closed loop pulsating heat pipes. Applied Thermal Engineering. 2008;28:49-59.

[17] Shafii MB, Faghri A, Zhang Y. Thermal modeling of unlooped and looped pulsating heat pipes. Journal of Heat Transfer. 2001;123:1159-72.

[18] Khandekar S, Groll M. On the definition of pulsating heat pipes: an overview. Proceedings of the Fifth Minsk International Seminar; 2003.

[19] Khandekar S, Panigrahi P, Lefèvre F, Bonjour J. Local hydrodynamics of flow in a pulsating heat pipe: A review. Frontiers in Heat Pipes. 2010;1:1-10.

[20] Riehl RR. Characteristics of an open loop pulsating heat pipe. SAE Technical Paper; 2004.

[21] Pachghare P, Mahalle A. Thermal performance of closed loop pulsating heat pipe using pure and binary working fluids. Frontiers in Heat Pipes. 2012;3:1-6.

[22] Tang X, Sha L, Zhang H, Ju Y. A review of recent experimental investigations and theoretical analyses for pulsating heat pipes. Frontiers in Energy. 2013;7:16173.

[23] Pachghare P, Mahalle M, Khedkar S. Effect of Working Fluid on Thermal Performance of Closed Loop Pulsating Heat Pipe: A Review. International Journal of Computer Applications. 2012;9:27-31.

[24] Meena P, Rittidech S, Tammasaeng P. Effect of inner diameter and inclination angles on operation limit of closed-loop oscillating heat-pipes with check valves. American Journal of Engineering and Applied Sciences. 2008;1(2):100-3.

[25] Charoensawan P, Khandekar S, Groll M, Terdtoon P. Closed loop pulsating heat pipes: Part A: parametric experimental investigations. Applied Thermal Engineering. 2003;23:2009-20.

[26] Rama Narasimha K, Sridhara S, Rajagopal M, Seetharamu K. Influence of heat input, working fluid and evacuation level on the performance of pulsating heat pipe. Journal of Applied Fluid Mechanics. 2012;5(2): 33-42.

[27] Rama Narasimha K, Varadarajan V, Pundarika G, Narasimha KR. Experimental investigation and performance evaluation of a closed loop pulsating heat pipe. Journal of Applied Fluid Mechanics. 2013;6(2): 267-75.

[28] Zhang X. Experimental study of a pulsating heat pipe using FC-72, ethanol, and water as working fluids. Experimental Heat Transfer. 2004;17:47-67.

[29] Halimi M, Nejad AA, Norouzi M. A Comprehensive experimental investigation of the performance of closed-loop pulsating heat pipes. Journal of Heat Transfer. 2017;139:092003. 
[30] Kammuang-lue N, On-ai K, Sakulchangsatjatai P, Terdtoon P. Correlation to predict thermal performance according to working fluids of vertical closed-loop pulsating heat pipe. International Journal of Mechanical, Aerospace, Industrial and Mechatronics Engineering. 2014;8(5):954-62.

[31] Kammuang-lue N, Sakulchangsatjatai P, Terdtoon P. Effect of working fluids on thermal characteristic of a closed-loop pulsating heat pipe heat exchanger: A case of three heat dissipating devices. IEEE Electronics Packaging Technology Conference. 2012;142-7.

[32] Khandekar S, Charoensawan P, Groll M, Terdtoon P. Closed loop pulsating heat pipes Part B: visualization and semi-empirical modeling. Applied Thermal Engineering. 2003;23:2021-33.

[33] Rittidech S, Terdtoon P, Murakami M, Kamonpet P, Jompakdee W. Correlation to predict heat transfer characteristics of a closed-end oscillating heat pipe at normal operating condition. Applied Thermal Engineering. 2003;23:497-510.

[34] Charoensawan P, Terdtoon P. Nondimensional Correlation to predict the thermal performance of a horizontal closed-loop pulsating heat pipe. Proc 14th International Heat Pipe Conference. 2007;22-7.

[35] Kline SJ. Describing uncertainty in single-sample experiments. Mechanical Engineering. 1953;75:3-8.

[36] Katpradit T, Wongratanaphisan T, Terdtoon P, Kamonpet P, Polchai A, Akbarzadeh A. Correlation to predict heat transfer characteristics of a closed end oscillating heat pipe at critical state. Applied Thermal Engineering. 2005;25:2138-51.

[37] Taft B, Drolen B, Williams A. Working fluid selection for pulsating heat pipes. 42nd AIAA Thermophysics Conference. 2011;3763.

[38] Khandekar S, Schneider M, Schafer P, Kulenovic R, Groll M. Thermofluid dynamic study of flat-plate closed-loop pulsating heat pipes. Microscale thermophysical engineering. 2002;6:303-17.

[39] Khandekar S. Thermo-hydrodynamics of closed loop pulsating heat pipes. 2004.

[40] Rama Narasimha K. Studies on pulsating heat pipes. India: Visvesvaraya Technological University; 2010. 